\section{Musculoskeletal disorders and the Global Burden of Disease study}

\author{
Kjersti Storheim, John-Anker Zwart
}

Specific data on different musculoskeletal (MSK) disorders from the Global Burden of Disease (GBD) study will be presented in this ${ }^{1-3}$ and future issues of the journal. ${ }^{4-9}$ MSK disorders are the second most common cause of disability worldwide, measured by years lived with disability (YLDs), with low back pain being the most frequent condition. ${ }^{10}$ Disability due to MSK disorders is estimated to have increased by $45 \%$ from 1990 to 2010 , in particular osteoarthritis (OA), and is expected to continue to rise with an increasingly obese, sedentary and ageing population. ${ }^{10}$ The GBD study represents a huge and important effort that involves researchers and experts from different disciplines and countries with new statistical tools that provide us with valid information about the prevalence and burden of MSK disorders.

The specific conditions and disorders that will be addressed in this and forthcoming issues are low back pain, occupationally related low back pain, neck pain, $\mathrm{OA}$, rheumatoid arthritis (RA), gout, low bone mineral density and other MSK conditions. Osteoporosis was not considered a disease in the GBD study, but bone mineral density was included in the global burden estimates as a risk factor for fractures. The methodological challenges will be addressed in a separate paper in the current issue. Even though there are some limitations, this effort is important for several reasons. In addition to the scientific interest, the data present a global perspective of MSK health and outline the impact of MSK disorders on individuals as well as society. These results provide researchers, healthcare providers and patient organisations with an excellent opportunity to encourage and increase awareness among policy makers to strengthen research and funding in this field.

The most common MSK disorders are low back and neck pain, which are still

Communication and Research Unit for Musculoskeletal Disorders (FORMI), Oslo University Hospital and University of Oslo, Oslo, Norway

Correspondence to Dr John-Anker Zwart, Communication and Research Unit for Musculoskeletal Disorders (FORMI), Oslo University Hospital and University of Oslo, Oslo, N-0853, Norway; UXZWJO@ous-hf.no poorly understood conditions. The biopsychosocial model has informed standard treatment over the last number of decades, ${ }^{11}$ resulting in clinical guidelines promoting an approach where $85-90 \%$ of patients do not receive a patho-anatomical diagnosis. Clinicians are often left with a trial and error strategy regarding diagnostic investigation and treatment and apply generic symptomatic treatments such as advice to stay active and avoid bed rest, prescribing analgesic medications, providing reassurance and suggesting exercises. However, systematic reviews reveal that existing treatments have only small effects at best, regardless of whether interventions are based on biological, psychological or social approaches. ${ }^{12}$ There is the potential for better management by implementing effective health promoting actions $^{13}$ and evidence supporting the recommendation of preventive measures such as weight loss ${ }^{14}$ and exercise for low back pain. ${ }^{15}$ The introduction of the biopsychosocial model has increased understanding of the complexity of chronic low back and neck pain, but research consortiums question the interpretation and application of the model, especially the lack of focus on biomarkers, in an effort to minimise the current gap in the understanding of disease mechanisms. ${ }^{11} 12$ Even though there is good evidence to suggest that psychological constructs are significant predictors of outcomes such as more severe pain, greater functional disability and work loss, there is a strong need for better understanding of more specific factors, such as lifestyle, occupational and, in particular, biological factors, in order to improve diagnostic and therapeutic strategies and develop evidence-based preventive measures.

$\mathrm{OA}$ is the most common joint disorder, causing pain and functional disability. The burden due to $\mathrm{OA}$ is anticipated to further increase due to obesity and an ageing population. ${ }^{10} \mathrm{OA}$ is associated with lowgrade inflammation, ${ }^{16}$ but the underlying pathogenic mechanisms are not fully understood and currently there is no curative treatment. Management mostly depends on symptom state and the use of non-pharmacological and pharmacological therapy, with joint replacement as the treatment end point. Strong evidence supports exercise and weight loss for the management of OA, ${ }^{17} 18$ but there is room for improvement and the development of more specific and sensitive methods for early diagnosis, detailed phenotypic characterisation and targeted treatment for the different OA subgroups. ${ }^{19}$

However, over the last few decades there have been important advances in the diagnosis and treatment of some MSK disorders such as RA. The development of new and effective drugs for RA has improved long-term outcomes for patients and has also facilitated early diagnosis, allowing prompt treatment which improves functional outcome and prevents disability and joint damage. ${ }^{20} 21$ Nevertheless, some patients do not respond adequately to treatment or experience adverse effects resulting in subsequent discontinuation of treatment. This underlines the need for an individualised approach combining clinical, biological and genetic and epigenetic predictors in order to optimise treatment for RA patients. ${ }^{22}$

There is still a need for epidemiological studies and public health actions promoting lifestyle changes such as weight loss and physical activity. Furthermore, it is necessary to focus on the underlying biological mechanisms and encourage researchers to combine and integrate data derived from longitudinal population- based cohorts and biobanks with detailed phenotypic data from trajectory and clinical studies as well as biological material in order to validate and identify novel biomarkers and risk factors. Combining genetic, molecular, paraclinical and clinical information will facilitate the translation of findings from basic science to clinical applications such as future preventive, diagnostic and therapeutic strategies. This will enable us to understand the impact of a wide range of determinants and risk factors for the development of different MSK disorders from early to old age, and help us preserve good health and develop effective and affordable strategies in order to respond to the growing disease burden, changes in demographic patterns and an ageing population.

Contributors Both authors contributed to the manuscript and approved the final version.

Competing interests None.

Provenance and peer review Commissioned; externally peer reviewed.

To cite Storheim K, Zwart J-A. Ann Rheum Dis 2014;73:949-950.

Received 24 March 2014

Accepted 7 April 2014 


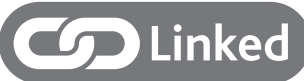

- http://dx.doi.org/10.1136/annrheumdis-2013-204431

- http://dx.doi.org/10.1136/annrheumdis-2013-204627

- http://dx.doi.org/10.1136/annrheumdis-2013-204763

- http://dx.doi.org/10.1136/annrheumdis-2013-204428

- http://dx.doi.org/10.1136/annrheumdis-2013-204344

http://dx.doi.org/10.1136/annrheumdis-2013-204631

- http://dx.doi.org/10.1136/annrheumdis-2013-204647

- http://dx.doi.org/10.1136/annrheumdis-2013-204680

- http://dx.doi.org/10.1136/annrheumdis-2013-204320

Ann Rheum Dis 2014;73:949-950.

doi:10.1136/annrheumdis-2014-205327

\section{REFERENCES}

1 Hoy D, March L, Brooks P, et al. The global burden of low back pain: estimates from the Global Burden of Disease 2010 study. Ann Rheum Dis 2014;73:968-74.

2 Driscoll T, Jacklyn G, Orchard J, et al. The global burden of occupationally related low back pain: estimates from the Global Burden of Disease 2010 study. Ann Rheum Dis 2014;73:975-81.

3 Hoy DG, Smith E, Cross M, et al. The global burden of musculoskeletal conditions for 2010: an overview of methods. Ann Rheum Dis 2014;73:982-9.

4 Hoy D, March L, Woolf A, et al. The global burden of neck pain: estimates from the Global Burden of Disease 2010 study. Ann Rheum Dis 2014. Published Online First 30 Jan 2014. doi:10.1136/ annrheumdis-2013-204431

5 Cross M, Smith E, Hoy D, et al. The global burden of rheumatoid arthritis: estimates from the Global Burden of Disease 2010 study. Ann Rheum Dis 2014. Published Online First 18 Feb. doi:10.1136/ annrheumdis-2013-204627
6 Cross M, Smith E, Hoy D, et al. The global burden of hip and knee osteoarthritis: estimates from the Global Burden of Disease 2010 study. Ann Rheum Dis 2014. Published Online First 19 Feb 2014. doi:10.1136/annrheumdis-2013-204763

7 Smith E, Hoy D, Cross M, et al. The global burden of gout: estimates from the Global Burden of Disease 2010 study. Ann Rheum Dis 2014. Published Online First 3 Mar 2014. doi:10.1136/annrheumdis-2013204647

8 Smith E, Hoy DG, Cross M, et al. The global burden of other musculoskeletal disorders: estimates from the Global Burden of Disease 2010 study. Ann Rheum Dis. Published Online First 3 Mar 2014. doi:10.1136/annrheumdis-2013-204680

9 Sànchez-Riera L, Carnahan E, Vos T, et al. The global burden attributable to low bone mineral density. Ann Rheum Dis 2014. Published Online First 1 Apr 2014. doi:10.1136/annrheumdis-2013-204320

10 Vos T, Flaxman AD, Naghavi M, et al. Years lived with disability (YLDs) for 1160 sequelae of 289 diseases and injuries 1990-2010: a systematic analysis for the Global Burden of Disease Study 2010. Lancet 2012;380:2163-96.

11 Hancock MJ, Maher CG, Laslett M, et al. Discussion paper: what happened to the 'bio' in the bio-psycho-social model of low back pain? Eur Spine J 2011;20:2105-10.

12 Pincus $T$, Kent $P$, Bronfort $G$, et al. Twenty-five years with the biopsychosocial model of low back pain-is it time to celebrate? A report from the twelfth international forum for primary care research on low back pain. Spine (Phila Pa 1976) 2013;38: 2118-23.

13 Buchbinder R, Jolley D, Wyatt M. 2001 Volvo Award Winner in Clinical Studies: effects of a media campaign on back pain beliefs and its potential influence on management of low back pain in general practice. Spine (Phila Pa 1976) 2001;26:2535-42.
14 Heuch I, Heuch I, Hagen K, et al. Body mass index as a risk factor for developing chronic low back pain: a follow-up in the Nord-Trondelag Health Study. Spine (Phila Pa 1976) 2013;38:133-9.

15 Choi BK, Verbeek JH, Tam WW, et al. Exercises for prevention of recurrences of low-back pain. Cochrane Database Syst Rev 2010;(1):CD006555.

16 Berenbaum F. Osteoarthritis as an inflammatory disease (osteoarthritis is not osteoarthrosis!) Osteoarthritis Cartilage 2013;21:16-21.

17 Nelson AE, Allen KD, Golightly YM, et al. A systematic review of recommendations and guidelines for the management of osteoarthritis: the chronic osteoarthritis management initiative of the U.S. Bone and Joint Initiative. Semin Arthritis Rheum 2013. doi:10.1016/j.semarthrit.2013.11.012 [Epub ahead of print 4 Dec 2013].

18 Svege I, Nordsletten L, Fernandes L, et al. Exercise therapy may postpone total hip replacement surgery in patients with hip osteoarthritis: a long-term follow-up of a randomised trial. Ann Rheum Dis 2013. Published Online First 20 Nov 2013. doi:10.1136/annrheumdis-2013-203628.

19 Bijlsma JW, Berenbaum F, Lafeber FP. Osteoarthritis: an update with relevance for clinical practice. Lancet 2011;377:2115-26.

20 Finckh $\mathrm{A}$, Liang $\mathrm{MH}$, van Herckenrode $\mathrm{CM}$, et al. Long-term impact of early treatment on radiographic progression in rheumatoid arthritis: a meta-analysis. Arthritis Rheum 2006;55:864-72.

21 Farragher TM, Lunt M, Fu B, et al. Early treatment with, and time receiving, first disease-modifying antirheumatic drug predicts long-term function in patients with inflammatory polyarthritis. Ann Rheum Dis 2010;69:689-95.

22 Plant D, Wilson AG, Barton A. Genetic and epigenetic predictors of responsiveness to treatment in RA. Nat Rev Rheumatol 2014. doi:10.1038/nrrheum.2014.16. [Epub ahead of print 18 Feb 2014]. 